\title{
From local to central: a network analysis of who manages plant pest and disease outbreaks across scales
}

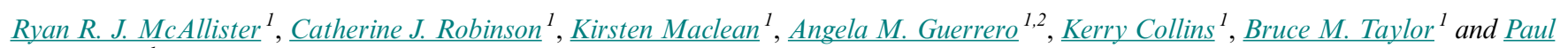 \\ J. De Barro $^{l}$
}

\begin{abstract}
One of the key determinants of success in managing natural resources is "institutional fit," i.e., how well the suite of required actions collectively match the scale of the environmental problem. The effective management of pest and pathogen threats to plants is a natural resource problem of particular economic, social, and environmental importance. Responses to incursions are managed by a network of decision makers and managers acting at different spatial and temporal scales. We applied novel network theoretical methods to assess the propensity of growers, local industry, local state government, and state and national government head offices to foster either within- or across-scale coordination during the successful 2001 Australian response to the outbreak of the fungal pathogen black sigatoka (Mycosphaerella fijiensis). We also reconstructed the response network to proxy what that network would look like today under the Australian government's revised response system. We illustrate a structural move in the plant biosecurity response system from one that was locally driven to the current top-down system, in which the national government leads coordination of a highly partitioned engagement process. For biological incursions that spread widely across regions, nationally rather than locally managed responses may improve coordination of diverse tasks. However, in dealing with such challenges of institutional fit, local engagement will always be critical in deploying flexible and adaptive local responses based on a national system. The methods we propose detect where and how network structures foster cross-scale interactions, which will contribute to stronger empirical studies of cross-scale environmental governance.
\end{abstract}

Key Words: banana; cross scale; Emergency Plant Pest Response Deed; EPPRD; exponential random graph model; false Panama

\section{INTRODUCTION}

The coordination of actions across natural resource problems requires management structures that collectively fit the spatial and temporal scales of the challenge at hand (Young 2002, Brondizio et al. 2009). We use "scale" to refer to the different spatial spheres of influence. At local scales, communities with good local knowledge may self-organize and regulate to ensure that their resources are used sustainably (Ostrom 2005). However, the longevity of local rules and behaviors depends on how they are nested in broader systems of government-led processes (Ostrom 2005, Agrawal et al. 2013, Mansbridge 2014). Assessing "institutional fit," i.e., how well environmental management matches the underpinning scale(s) of problems, is an emerging scholarly ambition that stands to identify institutional gaps and practical alternatives (see Robinson et al. 2011, Lebel et al. 2013). One approach to assessing institutional fit is through carefully designed questionnaires to measure the capacities of various stakeholders (Lebel et al. 2013). Good capacities to solve problems of fit can be both observed in, and facilitated by, networks that predispose across-scale interactions. Therefore, a complementary approach to analyzing capacities is to analyze scale matching by measuring the across-scale relationships between stakeholders operating at different scales. Recent studies have contributed to emerging methods of analyzing scale matching (Bergsten et al. 2014, Guerrero et al. 2015). We built on this work, treating governance as an interlinked network of decision makers and managers (Lubell 2013) and identifying not just if across-scale coordination happens, but where it does so.

Pest and pathogen threats to plants, referred to as plant biosecurity, constitute a natural resource management issue of particular economic, social, and environmental importance (Pejchar and Mooney 2009). Without management controls, it is estimated that exotic pests, weeds, and pathogens have the potential to inflict preharvest yield losses for global agriculture ranging from $44 \%-54 \%$ in wheat, $64-80 \%$ in rice, $58 \%-75 \%$ in maize, $73 \%-80 \%$ in potatoes, and $49 \%-69 \%$ in soybeans (Oerke 2006). Even with controls, losses average $28 \%, 37 \%, 31 \%, 40 \%$, and $26 \%$ in wheat, rice, maize, potatoes, and soybeans (Oerke 2006). The fungal pathogen rice blast (Magnaporthe oryzae) has been estimated to cause production losses sufficient to feed 60 million people per year (Pennisi 2010). Weeds have the potential to reduce global wheat yields by $18 \%-29 \%$ (Oerke 2006). The weed Striga hermonthica infests up to 40 million hectares, causing agricultural yield losses valued at US\$1 billion and affecting 100 million people (Pennisi 2010). Other weeds such as buffel grass (Cenchrus ciliaris) have commercial value, yet also have destructive environment impacts (Marshall et al. 2011).

Most scholarly attention around plant biosecurity has focused on furthering our knowledge of pest species and impacts; however, a focus on how tasks and knowledge are coordinated and shared is also crucial to ensure effective responses to biological invasions (Robinson and Whitehead 2003, Esler et al. 2010). Management requires actions along a full continuum of scales, with localized on-farm hygiene practices through international agreements on preborder quarantine forming key parts of control. The spread of risk occurs across regions and countries; hence, it requires that management occurs at a scale that matches the spatial and temporal scale of the risk, e.g., landscapes. Control and eradication will require containment of the incursion, extended community engagement, local and regional surveillance and

${ }^{1}$ Commonwealth Scientific and Industrial Research Organisation, ${ }^{2} \mathrm{ARC}$ Centre of Excellence for Environmental Decisions, The University of Queensland 
diagnostics, and industry and government collaboration. However, processes to guide effective local response will be inappropriate for guiding national coordination. One of the key determinants of success in managing an incursion is how well the suite of actions combine and coordinate to collectively match the spatial scale of the environmental problem dynamics to that of management (Cash et al. 2006, Termeer et al. 2010). We focused on institutional responses to plant pest and disease incursions using an Australian case study. "Response" represents one distinct aspect of overall plant biosecurity and requires a complexity of activities coordinated across scales. Scale has numerous definitions in the literature (Sayre 2005). We used scale to refer to the different spheres of influence that align broadly with the geographical boundaries of local agricultural enterprises, governments, and industry representatives.

The 2001 Australian response to the outbreak of black sigatoka (Mycosphaerella fijiensis), a banana fungal pathogen that can reduce banana yields by $50 \%$ (Pennisi 2010), provides a unique experiment for studying the structure of natural resource management networks across scales. Black sigatoka invoked an observable, unique response network linking stakeholders at grower, industry, and governmental scales in an ultimately successful eradication program. Using Exponential Random Graph Modeling (ERGM) to analyze the structural properties of the response, we built on a growing body of literature that seeks to understand the structure of networks by breaking them down into simple, theoretically relevant building blocks (Bodin and Tengö 2012, Lubell et al. 2014, McAllister et al. 2014), specifically exploring across-scale interactions (Bergsten et al. 2014, Gallemore et al. 2014, Guerrero et al. 2015). This analysis provides unique insight into how well a system for managing critical natural resource problems operates across local, state, and national scales. The more ad hoc, state government-led institutional framework in place for the black sigatoka incursion was replaced by a nationally centralized system in 2005 (Plant Health Australia 2005). To illustrate how Australia's new system may have potentially managed an incursion similar to the 2001 black sigatoka outbreak, we combined the black sigatoka data with new data sets from a subsequent incursion and the roles and responsibilities articulated under the new institutional settings.

\section{Black sigatoka and the Australian surveillance and response system}

Black sigatoka is endemic to most banana-growing regions in the world, and is a major biosecurity threat to the Australian banana industry (Marín et al. 2003). The disease is widespread in countries to Australia's north and is also found on a group of culturally distinct islands, the Torres Strait, in the far northeast of Australia. Where black sigatoka is endemic, growers control it with much higher doses of pesticides than currently used by Australian producers, resulting in greater production costs and environmental impacts (Cook et al. 2013). If the pathogen were to become established in a major Australian banana-growing region and eradication was not successful, the increased management required because of deleafing and higher frequency of chemical treatments would substantially increase production costs and likely cause a severe contraction of Australia's domestic banana supply (Cook et al. 2013).

Black sigatoka was first detected in Australia during a 1981 plant disease survey of the Torres Straits and Cape York Peninsula.
Since then, it has been found nine times on mainland Australia, all in the state of Queensland's tropical north. Before 2001, black sigatoka had never been detected in or near a commercial bananagrowing region (Peterson 2002). In April 2001, black sigatoka was detected during a routine survey on a number of wild plants within the Tully Banana Production Area, the largest commercial banana-growing region in Australia (Peterson 2002, Henderson et al. 2006, Cook et al. 2013).

Following the 2001 incursion, extensive surveys found that the outbreak was restricted to the Tully area. An eradication program funded by the Australian national government, all bananagrowing state governments (Western Australia, Northern Territory, Victoria, New South Wales, Queensland), the banana industry, and growers in the Tully area was finally approved in June 2001 and commenced in September 2001 (Peterson 2002). It consisted of an intense deleafing program, the establishment of an eradication success measure that equated to zero visible disease, surveillance of all banana stands in the region at 4- to 6week intervals by trained monitors, a weekly aerial spraying campaign, and the destruction of all unmanaged plants. Compulsory weekly meetings for all growers were also hosted on four nominated farms, so-called "shed meetings." Eradication activities were completed in May 2002, but monitoring continued over the next 12 months (Peterson 2002). No black sigatoka was detected after November 2001, and Australia was officially declared free of the pathogen in March 2005 (Henderson et al. 2006). In total, the eradication cost of the Tully outbreak was AUD\$17 million (Cook et al. 2013).

In 2001 many of the processes for responding to a plant pest or pathogen incursion were developed on a case-by-case basis by the state government in which the incursion occurred. Industry, state, and national governments negotiated an eradication cost-sharing deal concurrently with planning for on-ground responses. In 2005 Australia introduced a new nationally coordinated system based on the Emergency Plant Pest Response Deed (EPPRD; Biosecurity Emergency Preparedness Working Group 2012, Plant Health Australia 2005, 2011, 2013). EPPRD aimed to partly standardize how emergency responses are managed, coordinated, and paid for. A key aim of introducing EPPRD was to ensure rapid responses to incursions, particularly for responses that require cooperation across industries and/or state boundaries.

EPPRD is focused on a model of shared responsibility, which refers to a working partnership between national and state governments, industry, and the general community (Beale et al. 2008). To this end EPPRD defines specific roles that have shared responsibility and accountabilities for reporting and responding to incursions. These are shared among state government, both in the head office and at the site of the incursion, industry, and national government partners (Plant Health Australia 2013). The key players and the communication pathways for a generic EPPRD incursion from detection through to the operational phase of a response are diagrammatically represented in Figure 1 (also see Carnegie and Cooper 2011). This diagram was derived from the description of the general procedures, management structure, roles, and information flow system for the handling of EPPRD incursions at the national, state/territory, and local levels (Plant Health Australia 2013). As such, this institutional arrangement represents the intended governance response to an incursion event. 
Fig. 1. The Australian Emergency Plant Pest Response Deed: a simplified representation of the key players and the communication pathways in responding to a biosecurity incursion. Shaded boxes show various committees, management groups, or specialist teams that are formed when a risk is detected, with participating roles summarized. Unshaded boxes show defined roles that are central to information transfer within the network. Note that PHA refers to Plant Health Australia, and DoA to the Australian Department of Agriculture. See Plant Health Australia (2013) for more detail.

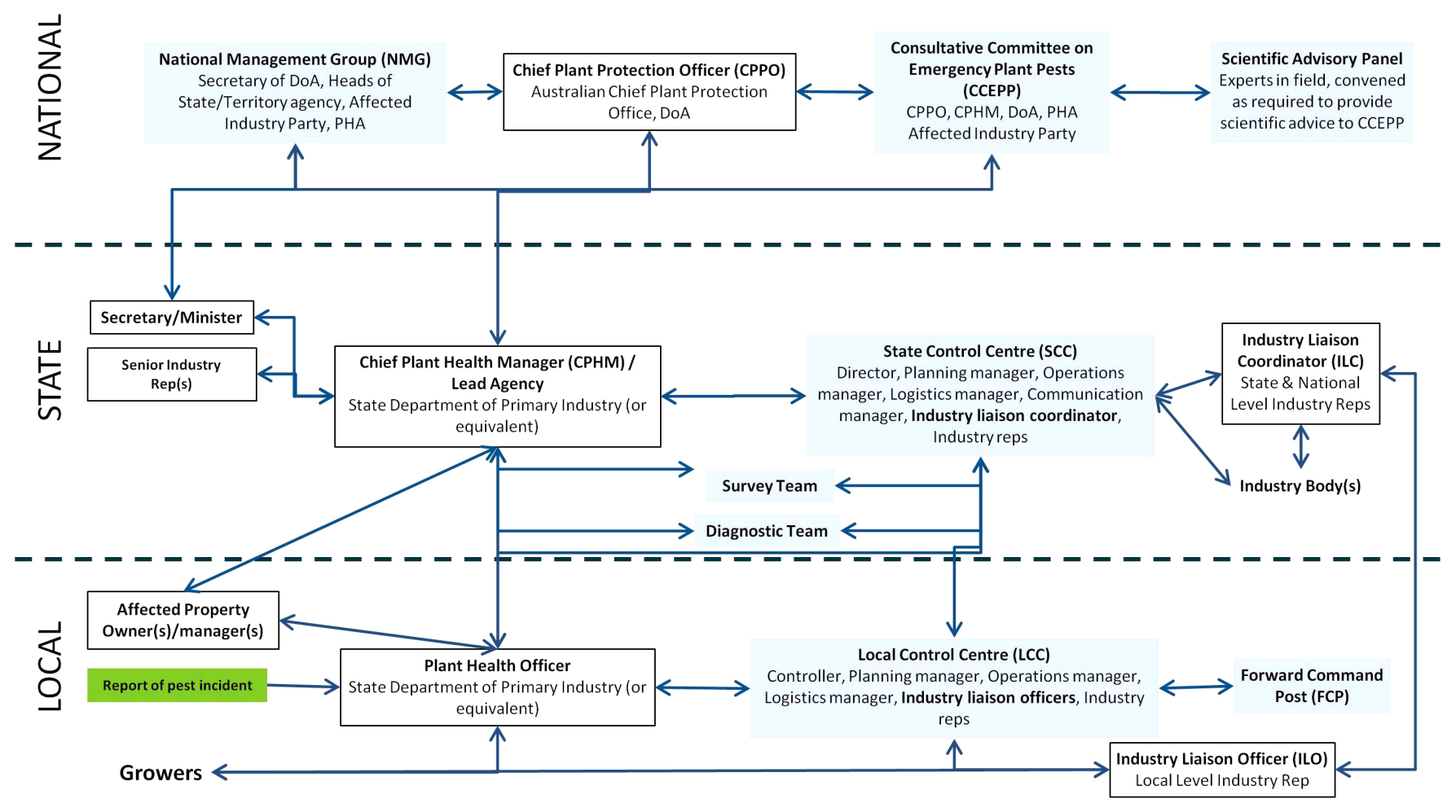

\section{METHODS}

\section{Bipartite and multilevel networks}

The EPPRD biosecurity system structure provides a clear example for explaining how our networks are defined. The EPPRD biosecurity system structure (Fig. 1) can be conceptualized as a network of two type of nodes: individuals with organizational positions, e.g., state chief plant health manager; and committee and working/expert groups, e.g., National Management Committee, Scientific Advisory Panel (Fig. 2). Individuals with organizational positions have a processbased, structured line of reporting. For example, if an incursion is suspected by a local plant health officer, the officer reports it to the state's chief plant health manager. If a suspected incursion is not ruled out, various committees and working groups with statutory guidance for attendance are formed. Although EPPRD provides guidance on which individuals should attend, the exact makeup of the various committees and groups will depend on the social, political, and technical specifics of each incursion.

Individuals, committees, and working group nodes can be connected via network ties. Ties between individual organizational actors, e.g., the state chief plant health manager, occur at the micro level, whereas ties between committees and working/expert groups, e.g., the National Management
Committee, are considered macro level (Fig. 2). Our focus was on how participation in various committees or working groups contributes to across-scale management within the multilevel networks of a plant biosecurity response. From a multilevel network perspective, this means a focus on only the meso-level ties (Fig. 2). Conceptually, the subset of meso-level ties can be represented as a bipartite network, i.e., a network with two distinct sets of nodes, and with ties only across these sets (Wang et al. 2013).

Although the EPPRD biosecurity system structure (Fig. 1) allows for an explanation of our data, our principal data set was for black sigatoka, for which the response was not managed under EPPRD. Instead, although nodes and ties were defined as above for the black sigatoka response network, the types of committees and working groups that were formed, as well as participation of individuals in these committees and working groups, were ad hoc and particular to the black sigatoka case. Response networks for pest and pathogen incursions both before and after the introduction of ERPRD have all been shaped by both formal organizational structures and informal preferences. However, the influence of informal preferences was much stronger before ERPRD (Beale et al. 2008). 
Fig. 2. Multilevel biosecurity network, with organizational actors (micro level) and committees and working groups (macro level) connected via ties representing processes and formal lines of communication. Organizational actors are connected to committees or working groups via ties based on their participation (meso level, solid ties). For definitions of node acronyms, see Fig. 1.

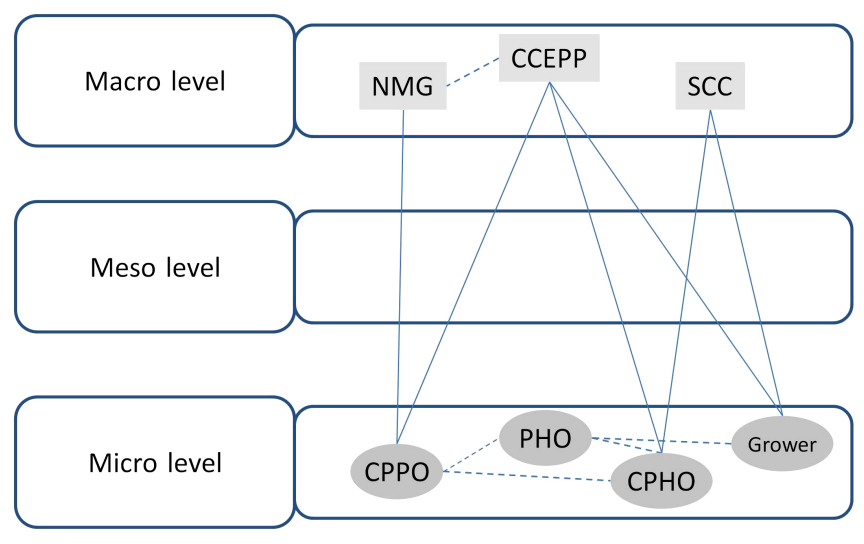

\section{Conceptual framework}

Conceptually, we built on a growing body of literature that seeks to understand the structure of networks by linking the distribution of configurations to theory (Fig. 3). These configurations are distinctive subpatterns that occur within a broader network; they are also called subnetworks, motifs, or building blocks. Bodin and Tengö (2012) and Bodin et al. (2014) linked social-ecological configurations to concepts of commonpool resource management. Guerrero et al. (2015) linked configurations based on social interactions to propensities to coordinate actions across scales. McAllister et al. (2014) explored participation of stakeholders in climate change policy forums, using constellations of forum-stakeholder configurations to identify stakeholders engaging as advocates.

Fig. 3. Examples where broader theoretical ideas have been linked subnetwork configurations.

Tragedy of the commons - where people (circles) compete for resource
usage (squares), the lack of social connection between the users suggests
unsustainable exploitation is likely (Bodin and Tengo 2012)

Our interest was in the biosecurity response system's ability to work across scales, which we gauged by exploring the balance between within- and across-scale configurations. In this regard we built our approach largely on the work of Guerrero et al. (2015). We sought to identify the types of configurations that are statistically over-represented or under-represented by stakeholders at local scales, i.e., grower, local industry, and local state government representatives, and at state and national government head office scales. Our conceptual framework explored network configurations that predispose interactions either within or across scales (Berardo 2014, Lubell et al. 2014, McAllister et al. 2014), and in either open or closed configurations (Fig. 4).

Fig. 4. Conceptual framework. Squares indicate committees or working groups, and circles indicate stakeholders. Shaded circles imply stakeholders must be of a given scale, e.g. grower, local industry or local state government representative, state or national government.

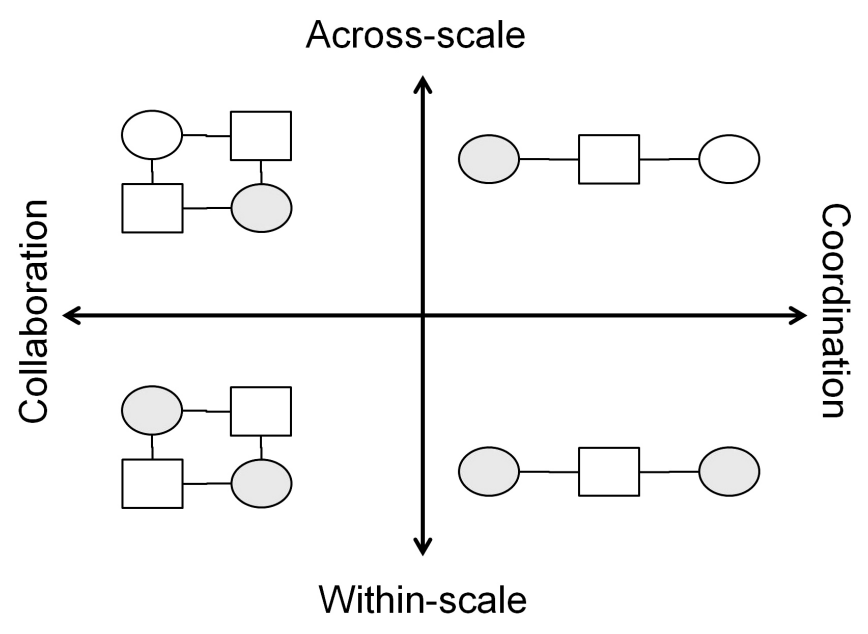

We refer to open configurations as determining coordination (Fig. 4 , right side). These tend to reveal bridging between otherwisedisconnected actors. Because otherwise-disconnected actors will tend to be connected to different sets of other actors, bridging lays the pathways for learning new information or opportunities (Granovetter 1973, Burt 2004). Rather than a social network, ours is one of institutional structure. Hence, rather than learning, these open, bridging ties predispose the ability to coordinate actions across the response network.

We refer to closed configurations as collaboration (Fig. 4, left side). These "cliques" occur where stakeholders participate in the same sets of committees and working groups. Such configurations also imply coordinating capacity, but their defining feature is their potential to additionally foster collaborative environments. These tightly bonded cliques persist either because participants share the same operational expectations and knowledge or, if they persist for other reasons, the persistence itself allows participants time to develop shared operational expectations. Sandström and Carlsson (2008) link such closure with high levels of cooperation and efficiency in delivering process-based tasks, particularly when the actors involved have the same mind set or objectives, i.e., homophily. 


\section{Data collection}

The network data set includes all relationships between the individual stakeholders who participated in the response to black sigatoka in 2001 and their participation in various committees and working groups directly associated with responding to the incursion. Although in more recent years record keeping with respect to incursions has improved dramatically, obtaining such information from Queensland state and Australian national governments was not possible for the 2001 event. Instead we compiled the response network using in-depth interviews with seven key stakeholders and published accounts (Peterson 2002, Henderson et al. 2006). The unpublished account in particular provides details on the stakeholders involved at local scales. The interviewees confirmed which stakeholders participated in which committees and working groups, and who the state and national government representatives were. A purposeful nonproportional quota sampling strategy (Tashakkori and Teddlie 2003) was used to select participants for interviews to ensure interviewees were chosen based on their involvement in black sigatoka surveillance, response, or subsequent review. Nodes in our network data were defined as individuals, but all individuals were categorized by their organizational role. Five types of stakeholders participated in our network: (1) property owners, who managed their agricultural enterprise; (2) local industry representatives; (3) local state government representatives, who were employed by the state government but lived in the region and worked on regional issues; (4) state government representatives working in administrative roles in the head office (Brisbane City); and (5) national government representatives (Australian Department of Agriculture).

A second data set was reconstructed to illustrate what the response network might have potentially looked like if the incursion had occurred under the new EPPRD response processes (Plant Health Australia 2013). Although this data set was not statistically comparable with our principal data set based on observed interactions for black sigatoka, the reconstructed data provided an important tool for contrasting institutional responses for biosecurity. The approach to creating this reconstructed data set was to collect new data on industry engagement from a recent 2011 banana pathogen incursion, reuse the grower engagement from the 2001 black sigatoka outbreak, and then structure and augment these elements using new EPPRD guidelines:

- The EPPRD contains duty statements for the key roles and responsibilities required during an outbreak, as well as guidelines for establishing and participating in key committees and working groups (Plant Health Australia 2013). These guidelines were used to generically populate these roles and committees for our reconstructed EPPRD response.

- In 2011, just north of the black sigatoka incursion, an outbreak of another serious Banana pathogen, Panama disease (Fusarium oxysporum f.sp. cubense) tropical race 4, was suspected. This was quickly shown instead to be the noninfectious disorder known as false Panama (de Beer et al. 2001), but not before local and state control centers had been established, including engagement with the banana industry. Note that EPPRD includes provision for industry engagement by state and national representatives. Because the Australia banana industry is overwhelmingly a northern Queensland industry, we treated all industry representatives as a form of local engagement. State government situation reports detail engagement with industry and their participation in committees. Although EPPRD shows the structure for how to engage with industry, the data from the false Panama incursion were used to proxy how industry bodies might participate in the hypothetical reconstructed EPPRD response network.

- In 2001, 131 growers were engaged in 4 groups through regular shed meetings with a local state government representative and a local industry representative in attendance. To proxy grower engagement for the reconstructed EPPRD response, we used the same 131 growers engaged in 2001 and likewise used the 2001 structure of shed meetings. The only assumed difference was that during the black sigatoka response the local state government representative was a very active, well-connected local diagnostic expert, but for the reconstructed EPPRD response, we assumed that a designated local industry liaison officer attended shed meetings instead, as guided by EPPRD (Plant Health Australia 2005).

Figure 5 depicts the data sets graphically. Table 1 totals the number of stakeholders involved in both the observed 2001 and the reconstructed EPPRD response.

Fig. 5. Graphical depiction of network data for (a) the 2001 black sigatoka outbreak and (b) the reconstructed Emergency Plant Pest Response Deed response. Squares indicate committees or working groups, and circles indicate individuals who participated in the response. Note that much of this information is considered sensitive; hence, the figure deliberately conceals detail.

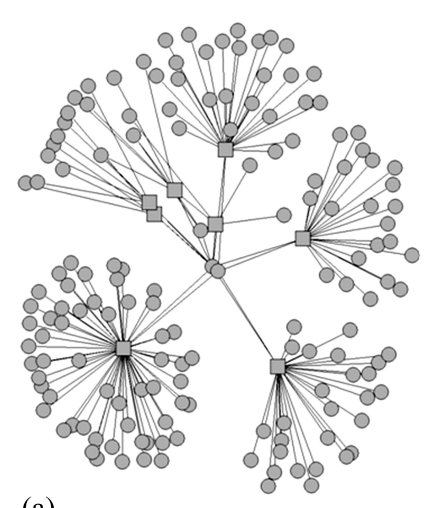

(a)

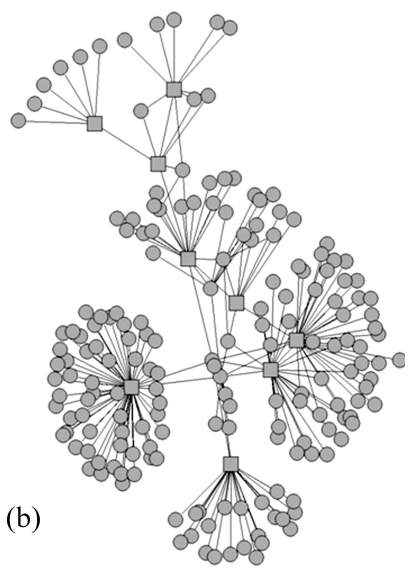

Exponential random graph modeling

Our approach built on advances in both statistical network methodology (ERGM; Frank and Strauss 1986, Wasserman and Pattison 1996, Robins and Morris 2007, Wang et al. 2013) and emerging approaches to its interpretation (Lubell et al. 2012, 2014, McAllister et al. 2014, Guerrero et al. 2015). ERGMs assume networks are the result of a stochastic process, treating an observed network as a single observation that can be compared 
with a distribution of all possible networks with a core set of identical characteristics, e.g., number of nodes and ties (Robins et al. 2007a). This allows for statistical interpretations on whether selected configurations are observed in a network more or less frequently than could be expected by chance alone. ERGMs allow for statistical inferences to be made without the need for multiple networks for comparison.

Table 1. Number of participants across all committees and working groups.

\begin{tabular}{|c|c|c|}
\hline Scale of participant & $\begin{array}{l}\text { Black sigatoka } \\
\text { (Mycosphaerella } \\
\text { fijiensis), } 2001\end{array}$ & $\begin{array}{l}\text { Reconstructed } \\
\text { Emergency Plant } \\
\text { Pest Response } \\
\text { Deed response }\end{array}$ \\
\hline Property owners (growers) & 131 & 131 \\
\hline $\begin{array}{l}\text { Local state-government } \\
\text { representatives }\end{array}$ & 9 & 7 \\
\hline State government (head office) & 5 & 21 \\
\hline National government & 1 & 9 \\
\hline Local industry representatives & 6 & 12 \\
\hline Total & 152 & 180 \\
\hline
\end{tabular}

In addition, most configurations in networks can be nested within other configurations. A configuration with four connected nodes also contains within it configurations with three connected nodes. ERGMs assess the relative frequency of configurations in a network given the observed frequency of other configurations, including those that are nested. In our case, ERGMs allowed us to test, e.g., the abundance of within-scale coordination configurations (Fig. 4) given the observed abundance of acrossscale collaborative configurations (Fig. 4). Note that in making accurate assessments of the representation of these configurations in our data, we controlled for the general level of activity displayed by each scale of stakeholder. This baseline activity can also be interpreted as a measure of how active stakeholders have been in the response network.

ERGMs estimate a coefficient for each configuration included in a model. The coefficients reflect the chances of observing ties between nodes, but their values cannot be interpreted directly. Instead, the signs of the coefficients quantify whether configurations are observed more, i.e., positive coefficient, or less, i.e., negative coefficient, than can be expected by chance alone, and the $t$ scores of the coefficients quantify whether this discrepancy between observation and expectation is statistically significant (Wang et al. 2009). One of the limitations of the ERGM approach is that where there is collinearity among model predictors, the maximum-likelihood algorithm used for estimating coefficients can fail to converge (Robins et al. 2007b). With the current methods, the selection of which configurations to include in an ERGM is therefore biased by which configurations allow model convergence. We took an applied approach, utilizing the software pNet for bipartite networks (Wang et al. 2009).

\section{RESULTS}

Our ERGMs included as many configurations from our conceptual framework as was feasible while allowing convergence (Figs. 4, 6). These configurations represent the distinction between within- and across-scale interactions for each scale/type of network participant (Table 1). The black sigatoka ERGM also included baseline activity configurations for each type of participant. In total, 15 configurations were included in the model. Of these 15,7 were either significantly over-represented or under-represented compared with what could be explained by chance alone (Fig. 6). Industry's within-scale coordinating role was significantly positive. Across-scale coordination was negative for state government, both in the head office and in the local region, and the national government. The baseline activity configurations were significantly positive for the local and state government head office and negative at the property scale. Note that the property owners' low level of activity is indicative of the fact that while they were important players in managing on-theground activities, they had only limited participation in the institutional arrangements for eradication.

Different convergence properties allowed for an ERGM for the reconstructed data that included 19 configurations, 14 of which were also included in the black sigatoka model. Of the 19 configurations, 11 were significantly over-represented or underrepresented compared with what could be explained by chance alone (Fig. 6). Property scale and state government both in the head office and in the local region had positive coefficients for within-scale coordination. Property, state (head office), and national governments had negative coefficients for across-scale coordination, whereas industry had a positive coefficient. The coefficient for the national government's across-scale collaboration configuration was positive. The baseline activity configurations were negative for property and industry, and positive for the national government.

\section{DISCUSSION}

\section{Black sigatoka, 2001}

The 2001 Australian eradication of black sigatoka was the first time a fungal pathogen had ever been eradicated from a commercial banana-growing district. Success was credited to effective partnerships (Henderson et al. 2006). The response mobilized significant local action, with local industry and growers making substantial contributions to the cause of eradication. Building on recent studies that use statistical network modeling (Gallemore et al. 2014, Guerrero et al. 2015, Lubell 2015), we explored whether the interactions observed in the institutional response for black sigatoka predisposed across-scale governance.

Our key metric for measuring the propensity for across-scale governance in response network was the balance between interactions indicating within-scale compared with across-scale interactions. Of the five types of stakeholders represented, i.e., property owners, government at local, state, and national scales, and industry, none had significantly more across-scale interactions than expected, although three had significantly less. In contrast, no stakeholder type had fewer within-scale interactions than expected, whereas industry stakeholders had more within-scale interactions, which is linked to a capacity to reach decisions and resolve conflict (Sandström and Carlsson 2008). The observed lack of across-scale interactions for local, state, and national government may limit the capacity to solve problems collectively (Sandström and Carlsson 2008) and the potential to respond at multiple levels. In other words, the network 
Fig. 6. Summary of Exponential Random Graph Modeling (ERGM) results. Counts show observed number of configurations in both networks; negative/positive ERGM parameters measure whether observed counts are fewer/ greater than expected by chance alone, with $t$ statistics used to access the statistical significance. As in Figure 4 , shaded circles in configurations imply that stakeholders must be of a given scale, e.g., grower, local industry or local state government representative, state or national government. EPPRD indicates Emergency Plant Pest Response Deed.

\begin{tabular}{|c|c|c|c|c|c|}
\hline \multirow[t]{2}{*}{ Configurations } & & \multicolumn{2}{|c|}{ Black Sigatoka, 2001} & \multicolumn{2}{|c|}{$\begin{array}{l}\text { Reconstructed EPPRD } \\
\text { response }\end{array}$} \\
\hline & & $\begin{array}{c}\text { Observed } \\
\text { count }\end{array}$ & $\begin{array}{c}\text { Parameter } \\
\text { (t-stat) }\end{array}$ & $\begin{array}{c}\text { Observed } \\
\text { count }\end{array}$ & $\begin{array}{c}\text { Parameter } \\
\text { (t-stat) }\end{array}$ \\
\hline \multirow{5}{*}{ Within-scale coordination } & Property & 2447 & $-0.02(-0.19)$ & 2447 & $0.16(3.40)^{* * *}$ \\
\hline & Local state-gvt & 28 & $-0.03(-0.12)$ & 21 & $0.61(2.41)^{* * *}$ \\
\hline & State & 10 & $0.94(1.52)$ & 135 & $0.25(4.61)^{* * *}$ \\
\hline & National & 0 & & 21 & $-0.05(-0.15)$ \\
\hline & Industry (local) & 10 & $0.64(1.74)^{*}$ & 0 & \\
\hline \multirow{5}{*}{ Across-scale coordination } & Property & 2709 & $0.05(0.51)$ & 2709 & $-0.13(-2.72)^{* * *}$ \\
\hline & Local state-gvt & 191 & $-0.25(-2.10)^{* *}$ & 173 & $0.06(1.05)$ \\
\hline & State & 29 & $-0.59(-3.25)^{* * *}$ & 188 & $-0.20(-3.40)^{* * *}$ \\
\hline & National & 7 & $-0.93(-2.45)^{* * *}$ & 42 & $-0.76(-4.86)^{* * *}$ \\
\hline & Industry (local) & 157 & $-0.13(-1.00)$ & 152 & $0.14(2.53)^{* * *}$ \\
\hline \multirow{5}{*}{ Within-scale collaboration } & Property & 0 & & 0 & \\
\hline & Local state-gvt & 1 & & 0 & \\
\hline & State & 0 & & 0 & \\
\hline & National & 0 & & 3 & $-1.69(-1.55)$ \\
\hline & Industry (local) & 0 & & 0 & \\
\hline \multirow{5}{*}{ Across-scale collaboration } & Property & 0 & & 0 & \\
\hline & Local state-gvt & 17 & $-0.01(-0.04)$ & 6 & $-0.65(-1.43)$ \\
\hline & State & 1 & & 3 & $-0.66(-1.30)$ \\
\hline & National & 0 & & 6 & $1.23(1.81)^{*}$ \\
\hline & Industry (local) & 15 & $-0.07(-0.37)$ & 6 & $-0.01(-0.08)$ \\
\hline \multirow{5}{*}{$\begin{array}{c}\text { Baseline activity } \\
\text { parameters } \\
-\square\end{array}$} & Property & 131 & $-2.01(-12.07)^{* * *}$ & 131 & $-2.13(-16.27)^{* * *}$ \\
\hline & Local state-gvt & 17 & $2.75(2.00)^{* *}$ & 12 & $0.07(0.07)$ \\
\hline & State & 6 & $3.63(1.77)^{*}$ & 23 & $0.86(1.28)$ \\
\hline & National & 1 & & 12 & $4.89(3.68)^{* * *}$ \\
\hline & Industry (local) & 11 & $0.90(0.59)$ & 5 & $-3.49(-3.52)^{* * *}$ \\
\hline
\end{tabular}

$* /^{* *} / * * *$ refer to 90,95 and $99 \%$ significance; blank denotes parameters for which either no estimates converged, or estimates converged but t-statistics showed that observed counts of configurations were not well explained by the model.

accommodates decisions to be made within scales, but did not predispose coordination of those decisions across scales. The obvious question is this: if the network failed to predispose acrossscale interactions and if across-scale interactions are important, then how did the eradication response network succeed?

Local action is critical in environmental management (e.g. Cash et al. 2003, Ostrom 2005, Marshall 2009). For plant biosecurity in agriculture, it is the action of locals who implement eradication response plans in a manner that is most appropriate to local topology, flora, fauna, and climate, and according to place-based knowledge, local political contexts, and social nuances. The role of the state and national scales relates to designing and funding plans. In the case of black sigatoka, there was a great deal of conflict across scales, to the point that local stakeholders, i.e., industry and local state government, essentially rejected the state's eradication plan and instead implemented their own project with industry backing (Peterson 2002, Henderson et al. 2006).

Our ERGM shows that with 9 local state government stakeholders participating in the response, their 17 network ties (Fig. 6) were statistically more than expected by chance, suggesting that in general, local state government stakeholders were particularly active in the response system. The ERGM also showed that the state government head office participants were relatively active on a per participant basis. However, although the state was active, the lack of across-scale interactions shows that although the 2001 black sigatoka response was a successful eradication (Henderson et al. 2006), this success was not based on collective action across scales. The response processes lacked consistency, and the absence of preagreed principles for determining cost-sharing across state and national governments and industry led to delays in on-ground eradication actions (Henderson et al. 2006, Beale et al. 2008).

\section{Illustrative hypothetical: black sigatoka under the Emergency Plant Pest Response Deed}

In 2005 , the state government-led institutional framework in place for the black sigatoka incursion was replaced by the nationally centralized EPPRD system (Plant Health Australia 2005). The EPPRD model is underpinned by shared responsibility, which more clearly articulates roles and responsibilities for a broader set of stakeholders and includes a much more central role for the national government in terms of negotiating financing of eradication attempts. As part of EPPRD, 
new capacities and roles for managing biosecurity were created at the national level.

Relatively few incursions have ever activated EPPRD, and those that have were from contexts and situations sufficiently different from black sigatoka to make comparisons hard to draw. Hence, to build a picture of how EPPRD may have played out for the black sigatoka outbreak, we used a reconstructed data set. There are limitations in comparing this hypothetical reconstructed data set with our observed data in any statistical sense because the data collection processes were different, and we need to acknowledge that every eradication response is highly stochastic. However, the comparison is a useful tool for illustrating structural changes in biosecurity.

Our key metric for measuring the propensity for across-scale governance in the response network was the balance between interactions indicating within-scale compared with across-scale interactions. For the hypothetical reconstructed scenario, our results showed that the network contained distinctive strengths in both within-scale and across-scale interactions. Of the five types of stakeholders represented, property owners and local and head office state government stakeholders had significantly fewer across-scale interactions than expected by chance alone, national stakeholders had more across-scale collaborative interactions, and industry stakeholders had more coordinating interactions. This contrasts with the black sigatoka data, which indicated that no stakeholder types had across-scale interactions. Within-scale interactions were also well represented, with property owners, state (head office), and national government stakeholders having significantly more across-scale interactions than could be explained by chance alone. Within-scale coordinating configurations suggest good conflict resolution and an ability to reach decisions (Sandström and Carlsson 2008). The across-scale collaborative and coordinating configurations additionally suggest that the network predisposes opportunities to share unique resources, including knowledge, and an ability to build and reinforce trust (Guerrero et al. 2015).

\section{Scale and Australian environmental governance}

Although EPPRD is more inclusive, the EPPRD's top-down plant biosecurity approach allows governments to more actively direct how stakeholders participate in plant biosecurity. In this regard plant biosecurity parallels broader trends in Australian natural resource governance (Wallington and Lawrence 2008). Australian governments are trending away from relying only on regulation to achieve policy goals and are now just as likely to be one of several players in cooperative or partnership-based programs (Lane et al. 2009, Taylor and Lawrence 2012). At face value, although this approach relies more on institutional collaboration than on regulation, there is something of a paradox in play. The paradox of this more collaborative or inclusive approach is that the broader rules that set the policy agenda, operational environment, and responsibilities for implementation in which collaboration occurs are increasingly framed by central government authority (Taylor 2010). In this way governments are devolving or sharing accountability for action while often recentralizing the locus of control of the implementation apparatus (Boonstra and Van Den Brink 2007).

These broader trends in Australian natural resource governance can be seen in our analysis. Our results illustrate the structural move in the plant biosecurity response system from one that was locally coordinated, with local industry as a key player, to the current top-down system, with the national government leading coordination of a highly partitioned engagement process and industry being engaged but not playing a central role. It also illustrates, albeit on hypothetical data, that EPPRD has a structure that is more likely to predispose better across-scale management compared with the more ad hoc response to black sigatoka in 2001. The quality and fit for purpose of knowledge are more important than the quantity (Crona and Bodin 2006, Vinke-de Kruijf et al. 2014), and in this regard how well local knowledge is used in broader management actions critically influences institutional outcomes (e.g., Measham 2007). Hence, although EPPRD better predisposed across-scale management, its effectiveness will rely on how a nationally coordinated network can develop mutual trust in the information exchanged between local and national scales (Juntti and Potter 2002).

\section{Detecting scale matching}

What constitutes good biosecurity is highly variable and dependent on local context. Prescribing a one-size-fits-all solution is unlikely to succeed (Cook et al. 2014). Instead, a system with robust partnerships and high levels of cooperation stands to give the system the flexibility needed to adapt a national response system to local circumstances. The mechanisms underpinning the importance of this flexibility relate to institutional fit (Brondizio et al. 2009). Fit refers to how well the capacities and institutional structures allow management to be aligned to the natural resources they seek to manage. Measuring these capacities is an important endeavor of research (Lebel et al. 2013). When management has a good capacity to solve problems of fit, acrossscale interactions are one of the results. We took this angle, focusing on detecting such spatial matching in the interactions involved in eradication responses.

Furthering the development of approaches for detecting the matching of spatial scales in environmental management based on the structure of stakeholder interactions is a key element of our work. Rather than focusing on explaining whole-of-network characteristics, we conceptualized networks as building blocks (Bodin and Tengö 2012) that can then be meaningfully linked to theoretical findings from diverse literatures. Our research demonstrates the functioning of the Australia plant biosecurity response system, but more broadly contributes to innovation in empirical methods to study environmental governance for complex and multiscalar challenges.

\section{CONCULSION}

Our analysis builds on novel network theory (Bodin et al. 2014, Guerrero et al. 2015) to compare the stakeholder response networks of the 2001 incursion of the fungal pathogen black sigatoka in Australia with a reconstructed account of what that network might potentially look like today under the country's revised response system. We found evidence that in 2001 the response was locally driven. There are limitations in comparing the 2001 observed response with our reconstructed, hypothetical incursion under the new incursion response system: EPPRD. The reconstructed data, however, do contribute to our understanding of changes in the biosecurity system, showing that coordination now occurs at much higher scales. In 2001 local participants were very active in the response. Under the new EPPRD, local 
participants were less active, and state and national stakeholders played key roles in across-scale coordinating capacity. Response to single incursions represents one distinct aspect of a plant biosecurity system that more broadly includes temporal dynamics involving surveillance, containment, and concurrent responses for multiple outbreaks. Studies that broaden our analysis to consider the more complete political economy of biosecurity, as well as building on our structural analysis by measuring capacities for solving institutional fit, remain two important avenues for future research.

\section{Responses to this article can be read online at: http://www.ecologyandsociety.org/issues/responses. php/7469}

\section{Acknowledgments:}

The authors would like to acknowledge the support of the Plant Biosecurity Cooperative Research Centre, established and supported under the Australian Government's Cooperative Research Centres Program. We received ethics clearance through CSIRO's Social Science committee (\#071/12). Many thanks to Plant Biosecurity Cooperative Research Centre Program Leader Professor Ruth Wallace for oversight, to stakeholders who provided their expert accounts of the black sigatoka outbreak, and to Carol Farbotko, Rieks Van Klinken, Peter Whittle, and two anonymous reviewers for critical comments.

\section{LITERATURE CITED}

Agrawal, A., D. G. Brown, G. Rao, R. Riolo, D. T. Robinson, and M. Bommarito II. 2013. Interactions between organizations and networks in common-pool resource governance. Environmental Science \& Policy 25:138-146. http://dx.doi.org/10.1016/j. envsci.2012.08.004

Beale, R., J. Fairbrother, A. Inglis, and D. Trebeck. 2008. One Biosecurity. A working partnership. Australian Government, Canberra, Australian Capital Territory, Australia.

Berardo, R. 2014. Bridging and bonding capital in two-mode collaboration networks. Policy Studies Journal 42(2):197-225. http://dx.doi.org/10.1111/psj.12056

Berardo, R., and J. T. Scholz. 2010. Self-organizing policy networks: risk, partner selection, and cooperation in estuaries. American Journal of Political Science 54(3):632-649. http://dx.doi. org/10.1111/j.1540-5907.2010.00451.x

Bergsten, A., D. Galafassi, and Ö. Bodin. 2014. The problem of spatial fit in social-ecological systems: detecting mismatches between ecological connectivity and land management in an urban region. Ecology and Society 19(4): 6. http://dx.doi. org/10.5751/ES-06931-190406

Biosecurity Emergency Preparedness Working Group. 2012. Biosecurity Incident Management System V1.0, 29 October 2012. Australian Government, Department of Agriculture, Fisheries and Forestry, Canberra, Australian Capital Territory, Australia.

Bodin, Ö., B. Crona, M. Thyreson, A.-L. Golz, and M. Tengö. 2014. Conservation success as a function of good alignment of social and ecological structures and processes. Conservation Biology 28(5):1371-1379. http://dx.doi.org/10.1111/cobi.12306

Bodin, Ö., and M. Tengö. 2012. Disentangling intangible socialecological systems. Global Environmental Change 22(2):430-439. http://dx.doi.org/10.1016/j.gloenvcha.2012.01.005

Boonstra, W. J., and A. Van Den Brink. 2007. Controlled decontrolling: involution and democratisation in Dutch rural planning. Planning Theory \& Practice 8(4):473-488. http://dx.doi. org/10.1080/14649350701664721

Brondizio, E. S., E. Ostrom, and O. R. Young. 2009. Connectivity and the governance of multilevel social-ecological systems: the role of social capital. Annual Review of Environment and Resources 34:253-278. http://dx.doi.org/10.1146/annurev.environ.020708.100707

Burt, R. S. 2004. Structural holes and good ideas. American Journal of Sociology 110(2):349-399. http://dx.doi.org/10.1086/421787

Carnegie, A. J., and K. Cooper. 2011. Emergency response to the incursion of an exotic myrtaceous rust in Australia. Australasian Plant Pathology 40(4):346-359. $\quad$ http://dx.doi.org/10.1007/ s13313-011-0066-6

Cash, D. W., W. Adger, F. Berkes, P. Garden, L. Lebel, P. Olsson, L. Pritchard, and O. Young. 2006. Scale and cross-scale dynamics: governance and information in a multilevel world. Ecology and Society 11(2): 8. [online] URL: http://www.ecologyandsociety. org/vol11/iss2/art8/

Cash, D. W., W. C. Clark, F. Alcock, N. M. Dickson, N. Eckley, D. H. Guston, J. Jäger, and R. B. Mitchell. 2003. Knowledge systems for sustainable development. Proceedings of the National Academy of Sciences of the United States of America 100 (14):8086-8091. http://dx.doi.org/10.1073/pnas.1231332100

Cook, D. C., N. P. Kristensen, S. Liu, D. R. Paini, P. J. Kerr, A. W. Sheppard, W. M. Lonsdale, R. R. J. McAllister, and P. J. De Barro. 2014. Plant biosecurity policy-making modelled on the human immune system: what would it look like? Environmental Science \& Policy 41:1-10. http://dx.doi.org/10.1016/j.envsci.2014.04.007

Cook, D. C., S. Liu, J. Edwards, O. N. Villalta, J.-P. Aurambout, D. J. Kriticos, A. Drenth, and P. J. De Barro. 2013. Predicted economic impact of black Sigatoka on the Australian banana industry. Crop Protection 51:48-56. http://dx.doi.org/10.1016/j. cropro.2013.03.016

Crona, B., and Ö. Bodin. 2006. What you know is who you know? Communication patterns amoung resource users as a prerequisite for co-management. Ecology and Society 11(2): 7. [online] URL: http://www.ecologyandsociety.org/vol11/iss2/art7/

de Beer, Z., J. M. Hernandez, and S. Sabadell. 2001. False Panama disorder. Musa Disease Fact Sheet 9. International Network for the Improvement of Banana and Plantein, Montpellier, France.

Esler, K. J., H. Prozesky, G. P. Sharma, and M. McGeoch. 2010. How wide is the "knowing-doing" gap in invasion biology? Biological Invasions 12(12):4065-4075. http://dx.doi.org/10.1007/ s10530-010-9812-x

Frank, O., and D. Strauss. 1986. Markov graphs. Journal of the American Statistical Association 81(395):832-842. http://dx.doi. org/10.2307/2289017 
Gallemore, C. T., R. Dini Prasti H., and M. Moeliono. 2014. Discursive barriers and cross-scale forest governance in Central Kalimantan, Indonesia. Ecology and Society 19(2): 18. http://dx. doi.org/10.5751/ES-06418-190218

Granovetter, M. S. 1973. The strength of weak ties. American Journal of Sociology 78:1360-1380. http://dx.doi.org/10.1086/225469

Guerrero, A. M., R. R. J. McAllister, and K. A. Wilson. 2015. Achieving cross-scale collaboration for large scale conservation initiatives. Conservation Letters, in press. http://dx.doi. org/10.1111/conl.12112

Henderson, J., J. A. Pattemore, S. C. Porchun, H. L. Hayden, S. Van Brunschot, K. R. E. Grice, R. A. Peterson, S. R. ThomasHall, and E. A. B. Aitken. 2006. Black Sigatoka disease: new technologies to strengthen eradication strategies in Australia. Australasian Plant Pathology 35(2):181-193. http://dx.doi. org/10.1071/AP06017

Juntti, M., and C. Potter. 2002. Interpreting and reinterpreting agri-environmental policy: communication, trust and knowledge in the implementation process. Sociologica Ruralis 42:215-232. http://dx.doi.org/10.1111/1467-9523.00212

Lane, M. B., C. J. Robinson, and B. T. Taylor. 2009. Contested country: local and regional natural resource management in Australia. CSIRO Publishing, Collingwood, Victoria, Australia.

Lebel, L., E. Nikitina, C. Pahl-Wostl, and C. Knieper. 2013. Institutional fit and river basin governance: a new approach using multiple composite measures. Ecology and Society 18(1): 1. http:// dx.doi.org/10.5751/ES-05097-180101

Lubell, M. 2013. Governing institutional complexity: the ecology of games framework. Policy Studies Journal 41(3):537-559. http:// dx.doi.org/10.1111/psj.12028

Lubell, M. 2015. Collaborative partnerships in complex institutional systems. Current Opinion in Environmental Sustainability 12:41-47. http://dx.doi.org/10.1016/j.cosust.2014.08.011

Lubell, M., G. Robins, and P. Wang. 2014. Network structure and institutional complexity in an ecology of water management games. Ecology and Society 19(4): 23. http://dx.doi.org/10.5751/ ES-06880-190423

Lubell, M., J. Scholz, R. Berardo, and G. Robins. 2012. Testing policy theory with statistical models of networks. Policy Studies Journal 40(3):351-374. http://dx.doi.org/10.1111/j.1541-0072.2012.00457. $\underline{\mathrm{x}}$

Mansbridge, J. 2014. The role of the state in governing the commons. Environmental Science \& Policy 36:8-10. http://dx.doi. org/10.1016/j.envsci.2013.07.006

Marín, D. H., R. A. Romero, M. Guzmán, and T. B. Sutton. 2003. Black sigatoka: an increasing threat to banana cultivation. Plant Disease 87(3):208-222. http://dx.doi.org/10.1094/PDIS.2003.87.3.208

Marshall, G. R. 2009. Polycentricity, reciprocity, and farmer adoption of conservation practices under community-based governance. Ecological Economics 68(5):1507-1520. http://dx.doi. org/10.1016/j.ecolecon.2008.10.008

Marshall, N. A., M. Friedel, R. D. van Klinken, and A. C. Grice. 2011. Considering the social dimension of invasive species: the case of buffel grass. Environmental Science \& Policy 14(3):327-338. http://dx.doi.org/10.1016/j.envsci.2010.10.005

McAllister, R. R. J., R. McCrea, and M. N. Lubell. 2014. Policy networks, stakeholder interactions and climate adaptation in the region of South East Queensland, Australia. Regional Environmental Change 14(2):527-539. http://dx.doi.org/10.1007/ s10113-013-0489-4

Measham, T. G. 2007. Building capacity for environmental management: local knowledge and rehabilitation on the Gippsland Red Gum Plains. Australian Geographer 38 (2):145-159. http://dx.doi.org/10.1080/00049180701392758

Oerke, E.-C. 2006. Crop losses to pests. Journal of Agricultural Science 144:31-43. http://dx.doi.org/10.1017/S0021859605005708

Ostrom, E. 2005. Understanding institutional diversity. Princeton University Press, Princeton, New Jersey, USA.

Pejchar, L., and H. A. Mooney. 2009. Invasive species, ecosystem services and human well-being. Trends in Ecology \& Evolution 24 (9):497-504. http://dx.doi.org/10.1016/j.tree.2009.03.016

Pennisi, E. 2010. Armed and dangerous. Science 327 (5967):804-805. http://dx.doi.org/10.1126/science.327.5967.804

Peterson, R. A. 2002. Black sigatoka eradication-controlled management program: Tully banana production area 2001-2002. Queensland Government, Department of Primary Industries and Fisheries, Brisbane, Queensland, Australia.

Plant Health Australia. 2005. Government and plant industry cost sharing deed in respect of emergency plant pest responses. Plant Health Australia, Canberra, Australian Capital Territory, Australia.

Plant Health Australia. 2011. PLANTPLAN: Australian Emergency Plant Pest Response Plan. Plant Health Australia, Canberra, Australian Capital Territory, Australia.

Plant Health Australia. 2013. PLANTPLAN: Australian Emergency Plant Pest Response Plan. Plant Health Australia, Canberra, Australian Capital Territory, Australia.

Robins, G., and M. Morris. 2007. Advances in exponential random graph ( $\mathrm{p}^{*}$ ) models. Social Networks 29(2):169-172. http:// dx.doi.org/10.1016/j.socnet.2006.08.004

Robins, G., P. Pattison, Y. Kalish, and D. Lusher. 2007a. An introduction to exponential random graph $\left(\mathrm{p}^{*}\right)$ models for social networks. Social Networks 29(2):173-191. http://dx.doi. org/10.1016/j.socnet.2006.08.002

Robins, G., T. Snijders, P. Wang, M. Handcock, and P. Pattison. $2007 b$. Recent developments in exponential random graph $\left(\mathrm{p}^{*}\right)$ models for social networks. Social Networks 29(2):192-215. http:// dx.doi.org/10.1016/j.socnet.2006.08.003

Robinson, C. J., R. D. Margerum, T. M. Koontz, C. Moseley, and S. Lurie. 2011. Policy-level collaboratives for environmental management at the regional scale: lessons and challenges from Australia and the United States. Society \& Natural Resources 24 (8):849-859. http://dx.doi.org/10.1080/08941920.2010.487848

Robinson, C. J., and P. Whitehead. 2003. Cross-cultural management of pest animal damage: a case study of feral Buffalo 
control in Australia's Kakadu National Park. Environmental Management 32(4):445-458. http://dx.doi.org/10.1007/s00267-003-0013-6

Sandström, A., and L. Carlsson. 2008. The performance of policy networks: the relation between network structure and performance. Policy Studies Journal 36(4):497-524. http://dx.doi. org/10.1111/j.1541-0072.2008.00281.x

Sayre, N. F. 2005. Ecological and geographical scale: parallels and potential for integration. Progress in Human Geography 29 (3):276-290. http://dx.doi.org/10.1191/0309132505ph546oa

Tashakkori, A., and C. Teddlie. 2003. Handbook of mixed methods sampling in social and behavioural research. Sage, London, UK.

Taylor, B. M. 2010. Between argument and coercion: social coordination in rural environmental governance. Journal of Rural Studies 26(4):383-393. http://dx.doi.org/10.1016/j.jrurstud.2010.05.002

Taylor, B. M., and G. A. Lawrence. 2012. Agri-political organizations in environmental governance: representing farmer interests in regional partnerships. Journal of Environmental Policy \& Planning 14(4):337-359. http://dx.doi.org/10.1080/1523908X.$\underline{2012.714565}$

Termeer, C. J. A. M., A. Dewulf, and M. van Lieshout. 2010. Disentangling scale approaches in governance research: comparing monocentric, multilevel, and adaptive governance. Ecology and Society 15(4): 29. [online] URL: http://www. ecologyandsociety.org/vol15/iss4/art29/

Vinke-de Kruijf, J., H. Bressers, and D. C. M. Augustijn. 2014. How social learning influences further collaboration: experiences from an international collaborative water project. Ecology and Society 19(2): 61. http://dx.doi.org/10.5751/ES-06540-190261

Wallington, T. J., and G. Lawrence. 2008. Making democracy matter: responsibility and effective environmental governance in regional Australia. Journal of Rural Studies 24(3):277-290. http:// dx.doi.org/10.1016/j.jrurstud.2007.11.003

Wang, P., P. Pattison, and G. Robins. 2013. Exponential random graph model specifications for bipartite networks - a dependence hierarchy. Social Networks 35(2):211-222. http://dx.doi. org/10.1016/j.socnet.2011.12.004

Wang, P., G. Robins, and P. Pattison. 2009. Pnet-program for the simulation and estimation of exponential random graph ( $\left.P^{*}\right)$ models. University of Melbourne, Melbourne, Victoria, Australia.

Wasserman, S., and P. Pattison. 1996. Logit models and logistic regressions for social networks: 1. An introduction to Markov graphs and p. Psychometrika 61(3):401-425. http://dx.doi. org/10.1007/BF02294547

Young, O. R. 2002. The institutional dimensions of environmental change: fit, interplay, and scale. MIT Press, Cambridge, Massachusetts, USA. 